\title{
Effects of DynEd Reading Course on Students' Reading Proficiency and Reading Motivation
}

DOI: https://doi.org/10.47175/rielsj.v2i3.307

\section{| Bai Donna S. Aliman |}

Mindanao State UniversityMaguindanao, Dalican, Datu Odin Sinsuat, Maguindanao, Philippines

bdsaliman@msumaguindanao. edu.ph

\begin{abstract}
Dynamic Education (DynEd) International Inc. is a leading provider of Interactive Language Program designed to enhance learners' English communication skills. This study aimed to determine the effect of the DynEd's Reading course on reading proficiency and reading motivation of the students in Mindanao State UniversityMaguindanao during $2^{\text {nd }}$ Semester of A.Y. 2017-2018. The study was conducted with the college students taking Job Enabling English Proficiency (JEEP) Start 2 courses. Sixty students were randomly selected among the eligible students to take Reading for Success course of the DynEd courseware. In this study, single group experimental with pretest and posttest design was used. The reading section of a TOEFL and Motivation for Reading Questionnaire (MRQ) by Wang and Guthrie (2004) were used as research instruments. The results showed that before DynEd Reading course was introduced, the students' reading proficiency level was described as low. However, after the 8-week long intervention using courseware, the students' reading proficiency level increased to intermediate level. Moreover, the students' intrinsic and extrinsic reading motivation level before and after the intervention were all found out to be in "motivated" level. It was also found out that comparison between the pretest and posttest in reading proficiency and intrinsic reading motivation were significant. It was then concluded that the DynEd Reading course is effective in improving the reading proficiency level and intrinsic reading motivation of the college students. The result implies that DynEd courseware is an effective tool to enhance the reading skills of the students.

KEYWORDS

effects; DynEd Reading course; reading proficiency; reading motivation.
\end{abstract}

\section{INTRODUCTION}

Reading is a requisite for most learning. The ability to read proficiently is essential skill needed to progress in school and in one's career. Proficient readers are more likely to perform well in their academic undertaking while learners with difficulty in reading are less academically engaged.

In the Philippines, most of the students lacks the ability to read and less motivated to partake in reading. In an interview with Dr. Quijano, former head of the DepEd Bureau of Elementary Education in 2007, she pointed out that the decline in reading comprehension drastically affect other learning areas. As mentioned in (Espejo, et. al. 2016), Borja (2009) and Luz (2007) stated that the reading problems are the main culprit for the poor performance of some students in the National Achievement Test (NAT). Although several text-based 
reading approaches have been utilized by reading teachers to help develop the reading proficiency of the students and to foster love for reading, still reading problems do exist. Such reading problems have been brought upon by the students when they enter tertiary level. Based on class observations, college students have noticeable reading difficulty and anxieties in the class. This pose a challenge to the teachers because if this is not addressed, it will persist and no other chances of formally addressing the problems once they leave the school or worst it may hinder them in completing their baccalaureate degrees.

However, the current educational system embraces the use of technology in the instruction. Also, in this digital age, learners are more interested in their lessons that use technology as means of teaching. As a result, technology-assisted programs become widespread and experts in language are continuously developing programs that aim to help students improve their English language skills.

Mindanao State University-Maguindanao is one of the universities in Mindanao that offers Job Enabling English Proficiency (JEEP) Courses as part of the curricula of the degree programs. This program was first introduced by GEM and USAID to help students in Mindanao achieve required proficiency level in the job market. A new reading course, Reading for Success, which was designed to develop academic reading skills and vocabulary for students ages 11-21, was added in the DynEd's courseware of the University in 2016.

Based on the researcher's observation, there are college students who have noticeable reading difficulty and hesitation to read in the class. The researcher believes that reading is a necessity of life that everybody must develop. Accordingly, reading skills influence students' well-being as adults. Adults with poor literacy skills find it difficult to function in society because many basic decision-making skills require reading proficiency.

Therefore, improving learners' reading proficiency by any means of teaching method is one of the fundamental undertakings of the institutions. It is in this context that the researcher is prompted to conduct a study on the possible effects of DynEd's Reading for Success Course as an alternative tool for improving the college students' reading proficiency and motivation.

This paper intended to determine the effect of the DynEd reading course in improving the reading proficiency and reading motivation of selected college students in MSUMaguindanao. Specifically, the study aimed to answer the following questions: 1 . What is the reading proficiency level of the students before the intervention? 2. What is the reading proficiency level of the students after the intervention? 3. What is the intrinsic reading motivation level of the students before the intervention? 4. What is the extrinsic reading motivation level of the students before the intervention? 5. What is the intrinsic reading motivation level of the students after the intervention? 6. What is the extrinsic reading motivation level of the students after the intervention? 7. Is there significant difference between the reading proficiency level of the students before and after the intervention? and 8. Are there significant differences between the intrinsic and extrinsic reading motivation level of the students before and after the DynEd reading course?

This study has the following statement of hypotheses:

Ho1: There is no significant difference between the students' mean scores in reading proficiency before and after DynEd Reading for Success Course.

Ho2: There is no significant difference between the students' weighted mean scores in intrinsic reading motivation before and after DynEd Reading for Success Course.

Ho3: There is no significant difference between the students' weighted mean scores in extrinsic reading motivation before and after DynEd Reading for Success Course. 


\section{RESEARCH METHODS}

This study used single group experimental with pretest and posttest design. Sixty students were purposively selected among all JEEP 2 students. The effect of DynEd Reading for Success on improving the respondents' reading proficiency and reading motivation was determined through analysis of their pre-test and post-test scores on TOEFL and Motivation for Reading Questionnaire (MRQ). It was conducted in Mindanao State UniversityMaguindanao which sustains JEEP (Job Enabling English Proficiency) Program for its good effect on enhancing the students speaking skills (Ulangkaya, 2015).

The descriptive statistics was used in the computation of the students mean scores. Paired t-test was also used to test the significant difference between the pretests and post-tests of the subjects. The following score range patterned from the TOEFL Test Scoring Guide was used for the interpretation of the students' performance level in reading. The range of scores were 0-14 (Low), 15-21 (Intermediate) and 22-30 (High). For Reading Motivation, the following scale was used in interpreting the result of the MRQ by factor: 3.50-4.00 (Very Motivated), 2.50-3.49 (Motivated), 1.50-2.49 (Slightly Motivated) and 1.00-1.49 (Not Motivated).

\section{RESULTS AND DISCUSSION}

\section{The Students' Reading Proficiency Level before DynEd Reading for Success Course}

Table 1 shows the frequency, percentage and description distribution of respondents' pretest scores in the TOEFL Model test administered before the intervention.

Table 1. Frequency, Percentage and Description Distribution of Respondents' Reading Proficiency Level before DynEd Reading for Success Course

\begin{tabular}{llll}
\hline Range of Score & Frequency & Percentage (\%) & Description \\
\hline $22-30$ & 2 & 3.33 & High \\
$15-21$ & 8 & 13.33 & Intermediate \\
$0-14$ & 50 & 83.33 & Low \\
\hline Total & 60 & 100.00 & \\
Mean $=\mathbf{9 . 5 2}$ (Low) & & & \\
\hline
\end{tabular}

The result shows that majority of the respondents ( 50 or $83.33 \%$ ) who had taken the Pretest on Reading Proficiency belonged to the score range of 0-14 labeled as low. This means that almost all respondents obtained a very low score. This implies that the respondents found difficulty in understanding new vocabulary words, analyzing word parts, and using context clues to guess the meaning of unknown words. This further implies that they struggled in identifying the main ideas and supporting details of the text and in understanding how ideas are connected within a text, the connections between sentences, and the links between paragraphs, which are critical to complete comprehension. Eight or 13.33 percent obtained a score ranging from 15-21 described as intermediate while only 2 or 3.33 percent scored within 22-30 labeled as high. These figures imply that only few of the respondents belonged to the higher levels of reading proficiency. This indicates that respondents under intermediate and high level must enhance and sustain their reading skills and reading habits throughout in order to increase their proficiency in reading.

In general, the overall weighted mean of 9.52 shows that most of the respondents have low reading proficiency level before the intervention of DynEd Reading for Success. This implies that the respondents need help to improve their reading skills. They must be given texts on a variety of topics and be taught to use their knowledge of grammar to understand 
difficult sections of a passage. They must also expand their vocabulary knowledge and study the organization of academic texts and overall structure of a reading passage.

According to Yossuke (2011), the goal of reading is to make the reader understand what the writer wants him/her to understand from the text and get the target message that the writer wants to convey. Reading comprehension process has many skills which play an important role in making the passage easy to be understood.

In connection with Yossuke's idea, this result suggests that their reading teacher or English teacher should design activities or provide intervention that can help the respondents improve their reading proficiency level.

\section{Students' Reading Proficiency Level after DynEd Reading for Success Course}

Table 2 shows the respondents' posttest scores in the TOEFL Model test administered after the intervention. Based on the Table, 29 or $48.33 \%$ of the respondents obtained a score within the range of 15-21 which is described as intermediate. This indicates that almost half of the total respondents obtained an average level of proficiency in reading after the intervention. It also reveals that most of the respondents who obtained a low score during the pretest have increased in their posttest after the intervention.

Table 2. Frequency, Percentage and Description Distribution of Students' Reading Proficiency Level after DynEd Reading for Success Course

\begin{tabular}{llll}
\hline Range of Score & Frequency & Percentage (\%) & Description \\
\hline $22-30$ & 9 & 15.00 & High \\
$15-21$ & 29 & 48.33 & Intermediate \\
$0-14$ & 22 & 36.67 & Low \\
\hline Total & 60 & 100.00 & \\
Mean $=\mathbf{1 5 . 3 5}$ (Intermediate) & & \\
\hline
\end{tabular}

However, there are 22 or 36.67 percent whose level is still described as low based on their posttest scores that fall within the range of 0-14. This means that almost half of the respondents have difficulty in reading as shown in their reading proficiency level. With this result, respondents are suggested to allocate more time to read in English and practice answering comprehension questions; to continue expanding their vocabulary knowledge; and to study the organization of academic texts and overall structure of a reading passage.

Furthermore, 9 or 15 percent of the respondents' scores fall within the range of 22-30 labeled as High. It means there are 9 respondents whose reading proficiency level belonged to High level after the intervention. This finding suggests that respondents with high reading proficiency level should keep on enhancing their reading skills through reading as much and as often as possible, continually expand vocabulary knowledge, and practice how ideas are connected within a text.

Finally, the result shows that the respondents' reading proficiency level after the DynEd Reading course has increased from low to intermediate with a mean score of 9.52 to 15.35 respectively.

Solanki (2012), as cited by Kocaman \& İskender (2016), mentioned that computer has become one of the most attractive aspects of modern life. Computer reading programs introduce an interactive and friendly environment through attractive animation, sound and demonstration. They give the students opportunity to work as individual or in a group to solve problems.

Further, Hartoyo (2010) as cited in Elradii (2014) mentioned that computer-reading programs could help students to improve their reading comprehension, to receive immediate 
feedback and not to continue practicing the wrong skills. It is important to match the kind of reading program with the right reading skill that is needed to be developed since the right program will strengthen their skills and improve their comprehension (Kocaman \& İskender, 2016).

With the positive result of this study, it can be said that DynEd Reading for Success promising effect in improving the reading difficulties of the students.

Students' Intrinsic Reading Motivation Level before DynEd Reading for Success Course Table 3 presents the weighted mean and description of Students' intrinsic reading motivation level before the intervention based on their rated responses in the following three factors of MRQ.

Table 3. Weighted Mean and Description Distribution of Students' Intrinsic Reading Motivation Level before DynEd Reading for Success Course

\begin{tabular}{ccc}
\hline Intrinsic Reading Motivation & Overall Weighted Mean & Description \\
\hline 1. Curiosity & 3.31 & Motivated \\
2. Involvement & 3.01 & Motivated \\
3. Preference for Challenge & 3.17 & Motivated \\
\hline Grand Mean & $\mathbf{3 . 1 6}$ & Motivated \\
\hline
\end{tabular}

Legend: 3.50-4.00 (Very Motivated), 2.50-3.49 (Motivated) 1.50-2.49 (Slightly Motivated) 1.00-1.49 (Not Motivated)

Result shows that among the three intrinsic motivations, the respondents find curiosity as the most intrinsically motivating factor as supported by a weighted mean of 3.31. It means that students are more motivated to read when the reading materials interest them and when they will learn new things, and information.

Moreover, Preference for Challenge obtained a weighted mean of 3.17 described as motivated. This means that the respondents can read difficult reading materials if the materials are interesting. They also like reading materials that make them think. The result concurs to the idea that when faced with difficult texts, an intrinsically motivated reader will persist and exert more effort than readers who are not intrinsically motivated to resolve conflicts and make connections with prior knowledge (Becker et al., 2010).

Furthermore, involvement has a weighted mean of 3.01 labeled as motivated. This entails that respondents are also motivated to read when the reading materials are in line with their specialized field or when they can relate to what they read. Respondents' involvement to the text is also manifested in making pictures of what they read in their mind.

Above findings agrees to Becker et al., (2010) who stated that sources of intrinsic motivation include positive reading experiences, books regarded as pleasurable, realizing the personal importance of reading, and interest in the topic read. All of these sources are found motivating by the respondents.

Furthermore, the respondents' grand mean in intrinsic reading motivation before the DynEd Reading for Success is 3.16 labeled as motivated. This means that the respondents rated most of the items of the three factors with higher points. Thus, based on the grand mean of 3.16, it can be said that the respondents are intrinsically motivated enough to engage in reading even before the intervention.

Wang \& Guthrie (2004) maintained that intrinsic motivation is critical to successful reading. Students who are engaged and intrinsically motivated to read are reported to have high satisfaction with their reading experiences and therefore engage in reading more often, which leads to improved learning, increased reading skill, and higher academic achievement (Becker et al., 2010). 
Students' Extrinsic Reading Motivation Level before DynEd Reading for Success Course Table 4 presents the weighted mean and description of students' extrinsic reading motivation level before the intervention based on their rated responses in the five particular factors of MRQ.

Table 4. Weighted Mean and Description Distribution of Students' Extrinsic Reading Motivation Level before DynEd Reading for Success Course

\begin{tabular}{rlc}
\hline Extrinsic Reading Motivation & Overall Weighted Mean & Description \\
\hline 1. Recognition & 2.95 & Motivated \\
2. Grades & 2.87 & Motivated \\
3. Social reading & 2.39 & Slightly Motivated \\
4. Competition & 2.73 & Motivated \\
5. Compliance & 3.12 & Motivated \\
\hline Grand Mean & $\mathbf{2 . 8 1}$ & Motivated \\
\hline
\end{tabular}

Legend: 3.50-4.00 (Very Motivated), 2.50-3.49 (Motivated) 1.50-2.49 (Slightly Motivated) 1.00-1.49 (Not Motivated)

Based on their responses, respondents obtained a weighted mean of 1.79 in a particular item under Social reading factor which is "I like to visit the library often to read English books or borrow English books". This means that respondents seldom visit the library for reading purposes. The result of social reading concurs to various researches that students start motivated and very eager to learn but this motivation towards reading slowly decreases, as they get older because of environmental and social factors (Guthrie, Hoa, Wigfield, Tonks, Perencevich, 2006).

On the other hand, compliance factor has the highest weighted mean of 3.12 described as motivated. This indicates that the respondents are motivated to read in English to meet an external goal or requirement. According to Ryan \& Connell (1989), the reason for this kind of reading is external motivation. The students did not choose this reason but because of the external pressure, thus this reading will be avoided if possible.

All other factors namely recognition, grades, and competition obtained a relatively the same weighted means of $2.95,2.87$, and 2.73 respectively all described as motivated. This reveals that respondents are motivated in these factors.

In general, result shows that the grand mean of the respondents in extrinsic reading motivation is 2.81 labeled as motivated. Hence, in overall respondents are extrinsically motivated to read before the intervention. Meaning they engage in reading because they want to be recognized, get high grades, compete with their peers, comply with the requirement of their teachers, and the need to share their experience and knowledge to their friends and family.

According to Capen (2010), even if students have the skills and ability to read, they might not choose to read unless they are motivated. Ultimately, the level of motivation students come to school with will be affected by what occurs within the classroom (Becker, McElvany, \& Kortenbruck, 2010).

\section{Students' Intrinsic Reading Motivation Level after DynEd Reading for Success Course}

Table 5 displays the weighted mean and description of students' intrinsic reading motivation level after the intervention based on their rated responses in the following three factors of MRQ. 
Table 5. Weighted Mean and Description Distribution of Students' Intrinsic Reading Motivation Level after DynEd Reading for Success Course

\begin{tabular}{clc}
\hline Intrinsic Reading Motivation & $\begin{array}{c}\text { Overall Weighted } \\
\text { Mean }\end{array}$ & Description \\
\hline 1. Curiosity & 3.39 & Motivated \\
2. Involvement & 3.13 & Motivated \\
3. Preference for Challenge & 3.25 & Motivated \\
\hline Grand Mean & $\mathbf{3 . 2 6}$ & Motivated \\
\hline
\end{tabular}

Legend: $3.50-4.00$ (Very Motivated), 2.50-3.49 (Motivated) 1.50-2.49 (Slightly Motivated) 1.00-1.49 (Not Motivated)

Results in the Table 5 shows that the respondents' responses in the items of curiosity, preference for challenge, and involvement obtained the weighted means of 3.39, 3.25, and 3.13 respectively with involvement being the lowest in rate. The result means that the respondents have high regards to reading for Curiosity among all intrinsic factors as indicated by the highest weighted mean of 3.39 with a slight increase from their pretest mean. Moreover, Preference for Challenge obtained also an increased weighted mean of 3.25 but still belonged to motivated level. It means that after the intervention, the respondents are still interested to read challenging reading materials. Also, Involvement factor obtained the lowest weighted mean of 3.13 after the intervention but it has increased a bit higher compare to the other factor. It shows that the respondents find being involved in reading text motivating. Some researchers believed that students must be encouraged whenever possible to choose books they will enjoy so they will view reading as an integrated facet of daily life (Clark \& Poulton, 2011; Crow \& Small, 2011).

Generally, the respondents obtained a grand mean of 3.26, which is labeled as motivated. This shows that the respondents' grand mean in intrinsic reading motivation belongs to the same score range as before with a slight increase. This slight increase implies that there is still a change in the respondents' intrinsic motivation after the intervention.

This finding validates the research findings of Saeed Al Shebli (2014) that computer applications as instructional tools used to teach reading help increase the students' engagement in reading, promote reading comprehension, stimulate interest, and improve reading skills. She also concludes that the self-directed learning offered through the CALL program motivated learners and that they were more engaged and motivated to learn when given the chance to use CALL.

Further, the finding supports the claims of Wood, et al. (2012) who states that offering different kinds of technology in the classroom can motivate students to use technology more often. When teacher use different technologies, students become more involved in learning the subject and their passion for learning increases.

\section{Students' Extrinsic Reading Motivation Level after DynEd Reading for Success Course}

Table 6 exhibits the weighted mean and description of Students' extrinsic reading motivation level after the intervention based on their rated responses in the five particular factors of MRQ.

Table 6 shows that after the intervention, Compliance Factor remained as highest in weighted mean of 3.15 with a little increase from previous mean. Yet, it still belongs to the range described as motivated. This means that respondents still have high regards to reading for compliance reasons. It can be gleaned that among the factors of extrinsic motivation, the respondents of this study engage to reading because they want to obey what their teachers asked them to do and that they perceive finishing their reading task important. 
Table 6. Weighted Mean and Description Distribution of Students' Extrinsic Reading Motivation Level before DynEd Reading for Success Course

\begin{tabular}{rlc}
\hline Extrinsic Reading Motivation & Overall Weighted Mean & Description \\
\hline 1. Recognition & 3.06 & Motivated \\
2. Grades & 2.92 & Motivated \\
3. Social reading & 2.34 & Slightly Motivated \\
4. Competition & 2.89 & Motivated \\
5. Compliance & 3.15 & Motivated \\
\hline Grand Mean & $\mathbf{2 . 8 7}$ & Motivated \\
\hline
\end{tabular}

Legend: 3.50-4.00 (Very Motivated), 2.50-3.49 (Motivated) 1.50-2.49 (Slightly Motivated) 1.00-1.49 (Not Motivated)

As reflected in the Table, reading for recognition was rated second highest with a weighted mean of 3.06. Relating from the previous weighted mean of recognition, there is also a slight increase in the weighted mean but still falls under motivated. This means that the respondents keep on believing that recognizing them in their reading task increase their motivation to participate more in reading activities. This further indicates that receiving compliments from their teachers, peers, friends, and family and being rewarded because of their achievement in reading often motivate them to read more.

Data show that reading for grades obtained a weighted mean of 2.92 described as motivated. This portrays that the respondents are motivated to read when they get good grades in reading. They also believe that reading can help in getting high grades.

It is also shown in the table that competition has a weighted mean of 2.89 labeled as motivated. This means that the respondents are motivated to read because they want to be the best over their peers. There is also a slight improvement on their weighted mean in competition factor, thus implies that during the intervention, their competition level in the classroom increased. This could be associated with the self-paced nature of the reading intervention that influences this factor.

Falling behind all other factors is the social reading factor, which is continually described as slightly motivated as indicated by its weighted mean of 2.34 which is slightly lower than the previous weighted mean. The results show that reading for social reading is constantly viewed less motivating by the respondents. This finding implies that DynEd Reading for Success provides less opportunity for students' discussion and collaboration since students independently engage on their own study at their level and pace.

Wentzel (2005) said that when teachers support this need for collaboration by allowing students to share ideas and build knowledge together, a sense of belongingness to the classroom community is established, and the extension and elaboration of existing knowledge is facilitated. Students gain the perspective of others while debating topics in the classroom, extending their initial views. Students who work together on a reading task are combining their background knowledge and skill sets, learning from each other, and building a shared understanding of the material (Chinn, Anderson, \& Waggoner, 2001).

\section{Comparison between Respondents' Reading Proficiency Mean Scores}

Table 7 demonstrates the result of the comparison made between the pretest and posttest scores of the respondents in the TOEFL Model test. 
Table 7. Comparison between the Students' Reading Proficiency Mean Scores Before and After the Intervention

\begin{tabular}{|c|c|c|c|c|c|}
\hline Compared Variable & $\sum \mathbf{D}$ & $\sum \mathbf{D}^{2}$ & $\begin{array}{l}\text { Computed } \\
\text { t-Value }\end{array}$ & $\begin{array}{l}\text { Tabular t- } \\
\text { Value }\end{array}$ & Description \\
\hline $\begin{array}{l}\text { Reading Proficiency Before } \\
\text { Intervention (Pretest Score) } \\
\text { And } \\
\text { Reading Proficiency After } \\
\text { Intervention (Posttest Score) }\end{array}$ & 284 & 2,077 & 10.404 & \pm 2.000 & Significant \\
\hline 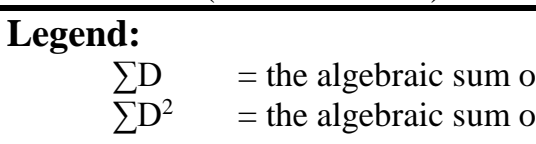 & & $\begin{array}{l}\text { ence } t \\
\text { e of th }\end{array}$ & $\begin{array}{l}\text { een the Prete } \\
\text { fference betw }\end{array}$ & $\begin{array}{l}\text { nd Posttest Scc } \\
\text { i the Pretest an }\end{array}$ & $\begin{array}{l}\text { res. } \\
\text { Posttest Scores }\end{array}$ \\
\hline
\end{tabular}

The data in Table 7 indicate the reading proficiency of the students before and after taking DynEd's Reading for Success Course. The t-test result reveals that there is significant differences between the pretest and posttest mean scores. It is indicated by the computed $\mathrm{t}$ value of 10.404, which is higher than the tabular t-value of \pm 2.00 . The result implies that the Reading for Success of the Dynamic Education is an effective intervention in enhancing students' reading proficiency.

Therefore, the null hypothesis stating that there is no significant difference between the students' pretest and posttest mean scores in reading proficiency before and after the intervention is rejected.

The improvement in reading proficiency could be understood in the context of selfdetermination theory, which states that students who believe they have more personal control over their learning and behavior are more likely to succeed than those who feel their learning is out of their hands (Ryan \& Deci, 2000). This is true as manifested in the significant improvement of the respondents' reading proficiency level after the intervention using the CALL program DynEd Reading for Success where they have personal control over their lesson.

In addition, studies show that CALL has a significant effect on improving reading achievement. Chappelle (2001) as mentioned by Rahmani (2013) suggested that technology incorporated in language learning can improve students' academic performance, enhance motivation, and promote learning.

\section{Comparison between Respondents' Reading Motivations Weighted Mean Scores}

Table 7 reveals the result of the comparison made between the respondents' rated responses before and after the intervention.

It is revealed in Table 8 that the students' intrinsic reading motivation has increased after taking DynEd Reading for Success. It is indicated by the computed t-value of 7.00 described as significant since it is higher than the tabular t-value of \pm 4.303 . Thus, the null hypothesis claiming that there is no significant difference between the weighted mean scores in intrinsic reading motivation before and after taking Reading for Success course is rejected.

Table 8. Comparison between the Students' Intrinsic and Extrinsic Reading Motivation Weighted Mean Scores before and After the Intervention

\begin{tabular}{llllll}
\hline Compared Variable & $\sum \mathbf{D}$ & $\sum \mathbf{D}^{2}$ & $\begin{array}{l}\text { Computed } \\
\text { t-Value }\end{array}$ & $\begin{array}{l}\text { Tabular } \\
\text { t-Value }\end{array}$ & Description \\
\hline A. Intrinsic Reading Motivation \\
$\quad$ Before Intervention
\end{tabular}




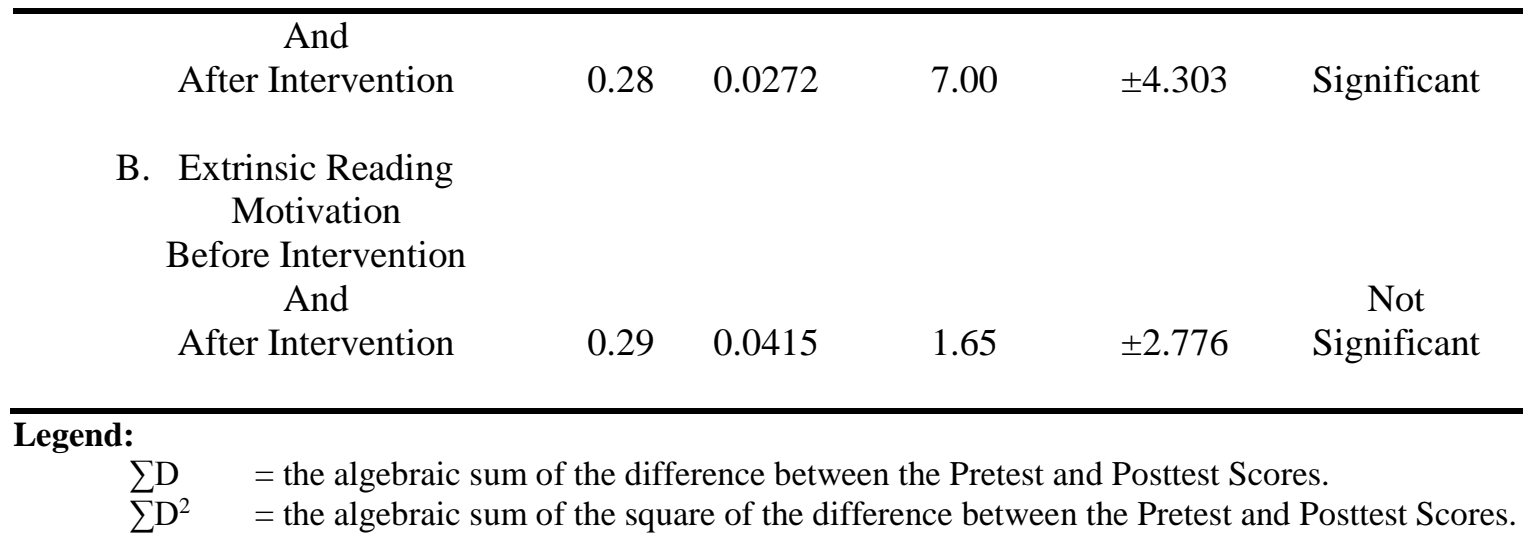

This result concurs to the findings of De Naeghel et al., (2012) who said that Intrinsic motivation is strengthened by the students' active involvement in learning as well as students taking ownership of their learning. Also, Guay et al. (2010) affirmed that superior student motivation is centered primarily on intrinsic motivation. This form of motivation is essential to the promotion of lifelong, voluntary reading (Melekoglu, 2011; Metsala et al., 1996; Pulfrey, Darnon, \& Butera, 2013 as cited in Houghton, 2015).

On the other hand, the data show that there is no significant difference on the students' extrinsic reading motivation weighted mean scores before and after Reading for Success course. It is revealed by its computed t-value of 1.65 described as not significant since it is lower than the tabular t-value of 2.776. The null hypothesis stating that there is no significant difference between the weighted mean scores in extrinsic reading motivation before and after taking Reading for Success course is therefore accepted. In other words, the DynEd Reading for Success course is more likely to develop the students' intrinsic reading motivation than extrinsic motivation.

Consequently, the reading teachers may incorporate extrinsic motivators to the classroom as a means of maintaining students' motivation to read. The use of extrinsic motivation is useful to motivate students to read and will eventually develop into intrinsic motivation to read (Colker, 2007; Guthrie et al., 2007). Extrinsic motivation may assist in motivating students to learn in areas where students lack interest (Lau, 2009).

\section{CONCLUSION}

Based on the findings of the study, it is concluded that Reading for Success course of DynEd is effective in improving students' reading proficiency. It is further concluded that reading for success is also effective in improving the students' intrinsic reading motivation. However, it helps a little in improving extrinsic motivation of the respondents, therefore less effective in this sense.

\section{ACKNOWLEDGMENT}

This achievement is wholeheartedly dedicated to my mother, to Norton, Yushramaica, Yuneezar Amarah, and Yussef Shakeel who are always been my source of strengths and motivation. Special thanks to all the people who, from their own little ways have contributed to the realization of this study. My endless gratitude to my Adviser, Prof. Marissa N. Parcon.

\section{REFERENCES}

Becker, M., McElvany, N., \& Kortenbruck, M. (2010). Intrinsic and extrinsic reading motivation as predictors of reading literacy: A longitudinal study. Journal of Educational Psychology. 
Capen, R. (2010). The role of the teacher and classroom environment in reading motivation. Illinois Reading Council Journal.

Chinn, C., Anderson, R.C., \& Waggoner, M.A. (2001). Patterns of discourse in two kinds of literature discussion. Reading Research Quarterly.

Clark, C., \& Poulton, L. (2011). Book ownership and its relation to reading enjoyment, attitudes, behavior and attainment: Some findings from the National Literacy Trust First Annual Survey. National Literacy Trust.

Colker, L.J. (2007). When children read because they want to, not because they have to. Retrieved from http://www.education.com/reference/article/Ref_When_Children_Read/

Crow, S.R., \& Small, R.V. (2011). Developing the motivational within: Using praise and rewards effectively. School Library Monthly.

De Naeghel, J., Van Keer, H., Vansteenkiste, M., \& Rosseel, Y. (2012). The relationship between elementary stidents recreational and academic rading motivation, reading frequency, engagement, and comprehension: a self-determination theory perspectives. Journal of Educational Psychology, https://doe.org/10.1037/a0027800

Espejo, C.T., Gutierrez, M. R.M., \& Macahilig, H.B.. (2016). The Comprehension Level of Selected Grade Four Pupils Vis-A-Vis Test and Test Type in Filipino. The Normal Lights, $10(1), 26-55$.

Guthrie, J.T., McRae, A., \& Klauda, S.L. (2007). Contributions of concept-oriented reading instruction to knowledge abot interventions for motivations in reading. Educational Psychologist.

Houghton, K.L. (2015). Impacts of Intrinsic and Extrinsic Motivation on Reading Achievement of First-Grade Students.

Kocaman, O., \& İskender, M. (2016). The effect of computer-assisted foreign language teaching on the student's attitude and success. Journal of Human Sciences, 13(3), 61246138. Retrieved from https://www.j-humansciences.com/ojs/index.php/IJHS/articles/ view/4346

Lau, K. (2009). Grade differences in reading motivation among Hong Kong primary and secondary students. British Journal of Educational Psychology.

Rahmani, M. (2013). The Effect of CALL on EFL Learners' Reading Comprehension and Attitude towards the Use of Technology.

Ryan, R.M., \& Deci, E. L., (2000). Self-determination theory and the facilitation of intrinsic motivation, social development, and well-being. American psychologist.

Shebli, S.A., \& Abdulla, A. (2014). Computer-Assisted Language Learning (Call) Impact on Students' Reading Achievement and Their Attitude towards Its Use.

Wang, J.H., Guthrie, J.T. (2004). Modeling the effect of intrinsic motivation, extrinsic motivation, amount of reading, and past and Chinese students. Reading Research Quarterly, Vol. 39

Wentzel, K. R. (2005). Peer Relationships, Motivation, and Academic Performance at School. In A. J. Elliot \& C. S. Dweck (Eds.), Handbook of competence and motivation (pp. 279-296). Guilford Publications.

Wood, E., Zivcakova, E., Gentile, P., Archer, K., De Pasquale, D., \& Nosko, A. (2012). Examining the impact of off-task multi-tasking with technology on real-time classroom learning. Computer \& Education.

Yossuke, Y. (2011). Definition of Reading Comprehension. Retrieved from https://www.yoyoii.blogspot.com/2011/06/definition-reading-comprehension.html 